\title{
Acute Physiological and Behavioral Effects of Intranasal Methamphetamine in Humans
}

\author{
Carl L Hart ${ }^{*, 1,2}$, Erik W Gunderson', Audrey Perez', Matthew G Kirkpatrick', ${ }^{1,2}$ Andrew Thurmond', \\ Sandra D Comer' and Richard W Foltin' \\ 'Department of Psychiatry, Division on Substance Abuse, New York State Psychiatric Institute, College of Physicians and Surgeons, Columbia \\ University, New York, NY, USA; ${ }^{2}$ Department of Psychology, Columbia University, New York, NY, USA
}

\begin{abstract}
Intranasal methamphetamine abuse has increased dramatically in the past decade, yet only one published study has investigated its acute effects under controlled laboratory conditions. Thus, the current study examined the effects of single-dose intranasal methamphetamine administration on a broad range of behavioral and physiological measures. Eleven nontreatment-seeking methamphetamine abusers (two females, nine males) completed this four-session, in-patient, within-participant, double-blind study. During each session, one of four intranasal methamphetamine doses $(0,12,25$, and $50 \mathrm{mg} / 70 \mathrm{~kg})$ was administered and methamphetamine plasma concentrations, cardiovascular, subjective, and psychomotor/cognitive performance effects were assessed before drug administration and repeatedly thereafter. Following drug administration, methamphetamine plasma concentrations systematically increased for $4 \mathrm{~h}$ postdrug administration then declined. Methamphetamine dose dependently increased cardiovascular measures and 'positive' subjective effects, with peaks occurring approximately 5-15 min after drug administration, when plasma levels were still ascending. In addition, cognitive performance on less complicated tasks was improved by all active methamphetamine doses, whereas performance on more complicated tasks was improved only by the intermediate doses ( 12 and $25 \mathrm{mg}$ ). These results show that intranasal methamphetamine produced predictable effects on multiple behavioral and physiological measures before peak plasma levels were observed. Of interest is the dissociation between methamphetamine plasma concentrations with cardiovascular measures and positive subjective effects, which might have important implications for potential toxicity after repeated doses.
\end{abstract}

Neuropsychopharmacology (2008) 33, I847- 1855; doi:I0.1038/sj.npp. I30I578; published online 12 September 2007

Keywords: methamphetamine abuse; cognitive performance; mood; plasma

\section{INTRODUCTION}

Although methamphetamine abuse has increased dramatically over the past decade, much of our knowledge about its acute effects in humans is anecdotal. The drug is frequently abused via the intranasal, i.v., and smoked routes (Domier et al, 2000; Community Epidemiology Work Group, 2005), but few studies have evaluated the acute effects of methamphetamine in humans using these routes of administration. The majority of studies conducted with humans have focused primarily on the cardiovascular and subjective effects produced by oral methamphetamine, a route of administration least often associated with abuse presumably due to its slow onset of effects. The onset of peak effects produced by oral methamphetamine does not occur until about 90 min after the administration (Hart et al, 2001a). By comparison, peak effects produced by intranasal, smoked,

*Correspondence: Dr CL Hart, Department of Psychiatry, Division on Substance Abuse, New York State Psychiatric Institute, College of Physicians and Surgeons, Columbia University, 105I Riverside Drive, Unit 120, New York, NY 10032, USA, Tel: + I 2125435884 , Fax: + I 212543 599|, E-mail: clh42@columbia.edu

Received 27 July 2007; revised I4 August 2007; accepted I5 August 2007 and i.v. methamphetamine occur within $15 \mathrm{~min}$ (Harris et al, 2003; Newton et al, 2005).

Given that the rapidity of drug-related effects is a critical determinant of abuse liability (Hatsukami and Fischman, 1996), it is surprising that only a few studies have examined methamphetamine-related effects via routes of administration other than oral (eg Cook et al, 1993; Mendelson et al, 1995; Newton et al, 2006). Although inhalation by smoking has been increasing in popularity in some cities in the western portion of the United States (Community Epidemiology Work Group, 2005), nasal insufflation appears to be the route of administration with which many individuals first experience problems related to excessive methamphetamine use. For example, in previous years, data from the National Institute on Drug Abuse's (NIDA) Community Epidemiology Work Group consistently indicated that intranasal use of methamphetamine was the second most common route among those seeking treatment for methamphetamine abuse in several regions assessed including Atlanta, Los Angeles, and Minneapolis (eg Community Epidemiology Work Group, 2007). It is possible that as methamphetamine use becomes more entrenched in various communities, abusers transition from intranasal use to inhalation in an effort to achieve even more rapid drug effects. 
Methamphetamine abuse has become more prevalent in the Eastern United States, but it is not the primary drug of abuse, nor is its use well established in most communities. Hence, nasal insufflation of methamphetamine remains the primary route by which the drug is abused. Indeed, in a sample of methamphetamine users in New York City, nearly all (96\%) reported using the drug primarily via the intranasal route (Halkitis et al, 2003). Reasons for preference of the intranasal route by many users could be related to the fact that they avoid potential blood-borne diseases associated with the i.v. route. Additionally, unlike the smoked and i.v. routes of administration, intranasal administration is far more convenient because drug use via this route does not require any special equipment (eg pipe, screen and needles).

Although a substantial number of individuals abuse intranasal methamphetamine, its effects are poorly understood. To date, only one published study has assessed the effects of methamphetamine via the intranasal route of administration under laboratory conditions (Harris et al, 2003). In that study, deuterated i.v. methamphetamine $(10 \mathrm{mg})$ was administered to experienced methamphetamine users over a 15 -min period in combination with unlabeled intranasal $(50 \mathrm{mg})$ or smoked $(40 \mathrm{mg})$ methamphetamine to determine absolute bioavailability. Methamphetamine was well absorbed following both the intranasal and smoked routes with bioavailabilities of $79 \%$ following intranasal administration and $67 \%$ following smoked administration. Both routes produced marked increases in positive subjective-effect ratings, blood pressure, and heart rate (HR). While the study by Harris and colleagues provided important information about the selection of a safe but active dose of intranasal methamphetamine, it did not include a placebo condition, only one active intranasal methamphetamine dose was tested, and few effects were assessed. As a result, information about the intranasal methamphetamine-related dose-response function on a broader range of dependent measures is unknown. Therefore, the present within-participants design study examined the effects of a range of single intranasal methamphetamine doses $(0,12,25$, and $50 \mathrm{mg} / 70 \mathrm{~kg})$ on several dependent variables, including methamphetamine plasma level, psychomotor/cognitive performance, and subjective and physiological effects. We hypothesized that methamphetamine would dose dependently increase plasma concentrations, positive subjective-effects ratings, and cardiovascular measures. No prediction was made regarding the influence of intranasal methamphetamine on psychomotor/cognitive performance because previous data were inconsistent when the effects of methamphetamine on the performance of wellrested individuals were assessed, ie Hart et al (2003) reported oral methamphetamine produced no significant performance effects, whereas Johnson et al (2000) reported the drug improved performance.

\section{METHODS}

\section{Participants}

Eleven research volunteers (mean age $( \pm S D)$ : $30.7 \pm 6.4$ years) completed this 2-week in-patient study: two were female (one black and one white) and nine were male (three black, three Latino and three white). Participants' formal education ranged from 12 to 17 years $($ mean $=13.7)$. They were solicited via word-of-mouth referrals and newspaper advertisements in New York City, and each signed a consent form that was approved by the Institutional Review Board of The New York State Psychiatric Institute (NYSPI). Prior to study enrollment, participants passed comprehensive medical and psychiatric evaluations and were within normal weight ranges according to the 1983 Metropolitan Life Insurance Company height/weight table (body mass index $( \pm$ SD) $24.1 \pm 4.4)$. All met DSM-IV criteria for current methamphetamine abuse $(N=2)$ or dependence $(N=9)$ and stated they were not seeking treatment for their methamphetamine use at the time of study participation. No participant met criteria for any other axis I disorder. They reported using methamphetamine $3.6 \pm 1.7$ (mean \pm SD) days per week and spending $\$ 100 \pm 75$ (mean \pm SD) per week on the drug (the current cost of street methamphetamine in the New York City area is $\$ 100-300$ per gram). All reported using the drug primarily via the intranasal route, and on average, participants reported using methamphetamine for $6.1 \pm 5.4$ (mean \pm SD) years. Six participants reported current cocaine use (1-4 times per week), seven reported current alcohol use (1.5-15 drinks per week), seven reported current marijuana use (1-6 times per week), and eight smoked 2-20 tobacco cigarettes per day. Other reported drug use was infrequent.

One additional white male participant began, but did not complete the protocol because he failed to comply with study procedures.

\section{Pre-Study Training}

Prior to study commencement, participants completed two training sessions (3-4h per session) on computerized psychomotor/cognitive tasks that would be used in the study and were familiarized with the laboratory and study procedures. The large amount of training is essential so that the tasks are well learned prior to study participation to minimize the effect of learning on task performance during the study. On a separate day, they received the largest intranasal methamphetamine dose $(50 \mathrm{mg} / 70 \mathrm{~kg})$ that would be tested during the study. This procedure provided participants with experience with the study drug and allowed for the monitoring of any potential unusual reactions to intranasal methamphetamine. No untoward events were noted.

\section{Design}

This within-participants study examined four intranasal methamphetamine doses $(0,12,25$, and $50 \mathrm{mg} / 70 \mathrm{~kg})$ over the course of 2 weeks. Each methamphetamine dose was tested once per participant, and all participants received the entire dose range of methamphetamine. A total of two methamphetamine doses were tested each week: one on Monday and one on Thursday. Each dose was separated by at least $72 \mathrm{~h}$ in which no drug was administered to limit the effects of previously administered doses. Subjective-effect ratings, psychomotor/cognitive performance, physiological effects, and methamphetamine plasma levels were assessed before and repeatedly after drug administration. For safety 
reasons, the first two participants were administered methamphetamine doses in ascending order. Thereafter, the dosing order was counterbalanced both within and between participants.

\section{Procedure}

Several days prior to beginning experimental sessions, participants were admitted onto the General Clinical Research Service at the NYSPI, where they resided until study completion. This arrangement ensured a sufficient drug washout period before study commencement and decreased the likelihood that nonstudy drugs would be consumed during the study. Throughout their participation, volunteers had access to television, the Internet, radio, telephone, videotaped movies, and tobacco cigarettes when not participating in a session. They could not leave the unit unescorted by research staff and could not receive visitors.

\section{Experimental Day}

All laboratory sessions began at approximately 0915. Each study day, volunteers who were tobacco cigarette smokers were asked to refrain from smoking $1 \mathrm{~h}$ preceding each session and smoking was not permitted during sessions. Before commencement of each session, volunteers consumed a light breakfast and gave a urine sample that was tested for several drug metabolites (amphetamines, cocaine, morphine derivatives, and THC). Following breakfast, they had a blood pressure cuff placed on the nondominant arm with connections to a Sentry II automated vital signs monitor. HR and blood pressure (systolic, SP; diastolic, DP) were assessed at baseline and then at predetermined time points; an ECG was also continuously monitored during each session. Subsequent to initiation of cardiac monitoring, participants sat in front of a computer with a mouse manipulandum, where blood samples were collected and they performed cognitive and subjective-effects batteries (for description, see below) before and repeatedly after drug administration. All blood samples were collected via an i.v. line, which was kept patent by a physiological saline solution drip. Methamphetamine was administered at about 1000. Cardiovascular values and blood samples were obtained 5, 15, 30,60, 90, 120, 180, and $240 \mathrm{~min}$ after methamphetamine administration. Subjective-effect ratings were completed at identical time points with two exceptions: no ratings were completed 30 -min postdrug administration. Performance was assessed 15, 60, 120, 180, and $240 \mathrm{~min}$ after drug administration. Three additional blood samples were collected at 6,12 , and $24 \mathrm{~h}$ after methamphetamine administration. In addition, a standardized selfselected lunch was served during each session following the 120-min assessments.

\section{Subjective-Effects and Cognitive/Psychomotor Battery}

The computerized visual analog scale (VAS) consisted of a series of 100-mm lines labeled 'not at all' at one end and 'extremely' at the other end. The lines were labeled with 'I feel', 'alert', 'anxious', 'a bad drug effect', 'clumsy', 'confused', 'content', 'depressed', 'dizzy', 'energetic', 'forgetful', 'friendly', 'a good drug effect', 'high', 'hungry', 'irritable', 'jittery', 'mellow', 'miserable', 'nauseous', 'on edge', 'paranoid', 'restless', 'sedated', 'self-confident', 'sleepy', 'social', 'stimulated', 'talkative', 'tired,' 'unmotivated', 'withdrawn', 'I am sweating', 'I am having difficulty concentrating', 'I have chills', 'I have a headache', 'I have muscle pain', 'I have an upset stomach', 'my heart is beating faster than usual', 'my nose is burning', 'my vision is blurred', and 'noises or sounds seem louder than usual.' Three VAS items were then used to operationalize drug craving and were labeled 'I want meth', 'I want alcohol', and 'I want a cigarette'. Each session, a drug-effect questionnaire (DEQ) was also completed 90 min after methamphetamine administration. Participants were required to rate 'good effects' and 'bad effects' from the drug on a five-point scale: $0=$ 'not at all' and $4=$ 'very much'. They were also asked to rate how 'strong' the drug effect was and their desire to 'take the drug again.' Lastly, participants were asked to rate how much they liked the drug effect on a nine-point scale: -4 indicated 'disliked very much', 0 indicated 'feel neutral, or feel no drug effect', and 4 indicated 'liked very much'. Finally, at the end of each session, participants were asked, 'How much would you pay for the dose you just received?' with a range of $\$ 0-20$.

The computerized cognitive/psychomotor task battery (Hart et al, 2006) consisted of a 3-min Digit-Symbol Substitution Task (DSST; McLeod et al, 1982), a 3-min repeated-acquisition task (Kelly et al, 1993), a 10-min divided attention task (DAT; Miller et al, 1988), a 10-min rapid information task (Wesnes and Warburton, 1983), and an immediate and delayed digit-recall task (Hart et al, 2001b).

\section{Drugs}

Methamphetamine $\mathrm{HCl}$, suitable for human use, was provided by the NIDA and prepared by the NYSPI Pharmacy. Lactose powder was used as a placebo and added to each methamphetamine dose $(12,25$, and $50 \mathrm{mg} /$ $70 \mathrm{~kg}$ ) to achieve a final weight of $60 \mathrm{mg} / 70 \mathrm{~kg}$. As a safety precaution, the maximum single methamphetamine dose administered did not exceed $60 \mathrm{mg}$, even if the participant weighed greater than $84 \mathrm{~kg}$.

A research nurse placed each dose in a small medicine cup, along with a plastic straw $(\sim 7 \mathrm{~cm})$. Participants were instructed to insufflate the entire dose within a 30 -s period in either one or two nostrils. We have previously used this procedure in studies evaluating intranasal cocaine and heroin (eg Foltin et al, 1988; Comer et al, 1997). All drug administrations occurred in a double-blind manner.

\section{Data Analysis}

Repeated-measures analyses of variance (ANOVA) with planned comparisons were used to determine the effects of methamphetamine on cardiovascular effects, subjective ratings, and cognitive/psychomotor performance. Dependent measures were analyzed using a two-factor repeatedmeasures ANOVA: the first factor was methamphetamine dose $(0,12,25$, and $50 \mathrm{mg} / 70 \mathrm{~kg})$ and the second factor was time (time and number of assessments varied depending on the measure, eg performance was assessed at time points baseline, $+15,+60,+120,+180$, and $+240 \mathrm{~min})$. For all 
analyses, ANOVAs provided the error terms needed to calculate planned comparisons that were designed to determine the effects of methamphetamine dose, ie $0 \mathrm{mg}$ $v s$ three active doses, $12 \mathrm{mg} v s$ two larger doses, and $25 v s$ $50 \mathrm{mg}$. Data were considered statistically significant at $P<0.05$, using Huynh-Feldt corrections where appropriate.

\section{RESULTS}

\section{Plasma Methamphetamine Levels}

Figure 1 (top left panel) shows methamphetamine plasma concentration as a function of methamphetamine dose and time. Methamphetamine plasma concentration was increased in a dose-dependent fashion $(\mathrm{F}(3,330)=121.57$, $P<0.0001)$. All active doses significantly differed from placebo, the 25-mg dose differed from the 12-mg dose, and the $50-\mathrm{mg}$ dose differed from the $12-$ and $25-\mathrm{mg}$ doses $(P<0.005$ for all conditions). Peak plasma concentrations were observed $4 \mathrm{~h}$ after methamphetamine administration and declined over the next several hours.

\section{Cardiovascular Effects}

Figure 1 (top right and bottom panels) displays cardiovascular measures as a function of methamphetamine dose and time. Methamphetamine systematically increased $\mathrm{HR}$ $(\mathrm{F}(3,240)=13.05, \quad P<0.0001), \quad$ SP $\quad(\mathrm{F}(3,240)=43.37$, $P<0.0001)$, and DP $(F(3,240)=33.52, P<0.0001)$. For all three measures, active methamphetamine-induced elevations were significantly different from placebo $(P<0.04)$. Regarding HR, the 50- and $25-\mathrm{mg}$ doses significantly increased beats per minute compared with the $12-\mathrm{mg}$ dose $(P<0.05)$. Regarding SP and DP, the $50-\mathrm{mg}$ dose was significantly different from the two other active doses $(P<0.0001)$. In contrast to peak methamphetamine plasma concentrations, peak cardiovascular effects of methamphetamine occurred within 15 min of drug administration.

\section{Subjective Effects}

Figure 2 illustrates the effects of methamphetamine on selected subjective-effect ratings over time. Notably, methamphetamine dose dependently increased ratings of 'good drug effect' $(\mathrm{F}(3,180)=14.93, P<0.001)$ and 'stimulated' $(\mathrm{F}(3,180)=11.03, P<0.001$; Figure 2 , upper panels $)$. All active methamphetamine doses were significantly different from placebo and the 50-mg dose significantly differed from the $12-$ and $25-\mathrm{mg}$ doses $(P<0.03)$. Methamphetamine also produced systematic decreases on ratings of 'hungry' $(\mathrm{F}(3,180)=11.65, P<0.003)$ and 'tired' $(\mathrm{F}(3,180)=10.77, \quad P<0.001$; Figure 2 , lower panels $)$.
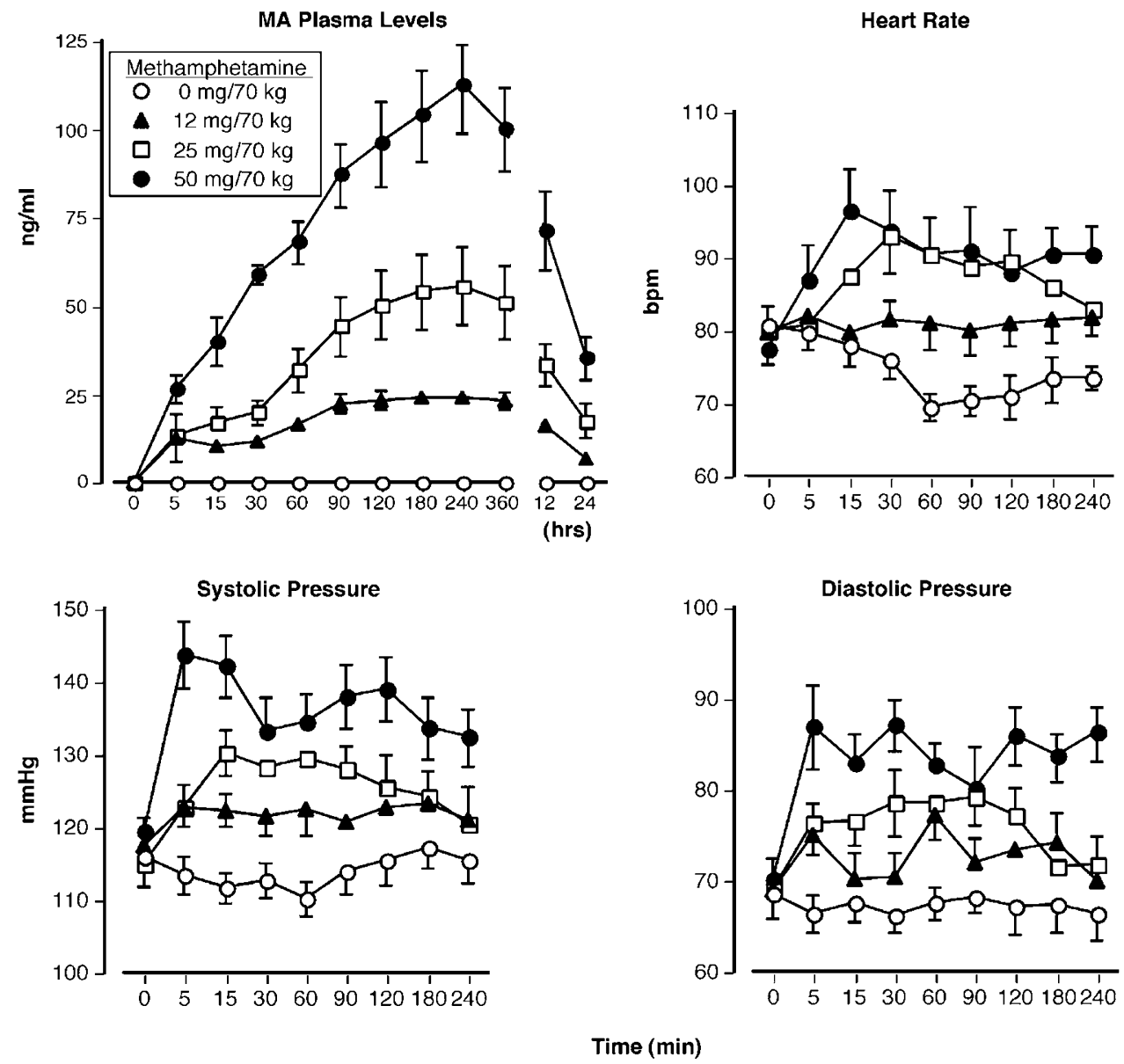

Figure I Upper panel (left): methamphetamine plasma levels as a function of methamphetamine dose and time. Upper panel (right): heart rate as a function of methamphetamine dose and time. Lower panels: systolic and diastolic pressure as a function of methamphetamine dose and time. Error bars represent one SEM. Overlapping error bars were omitted for clarity. 


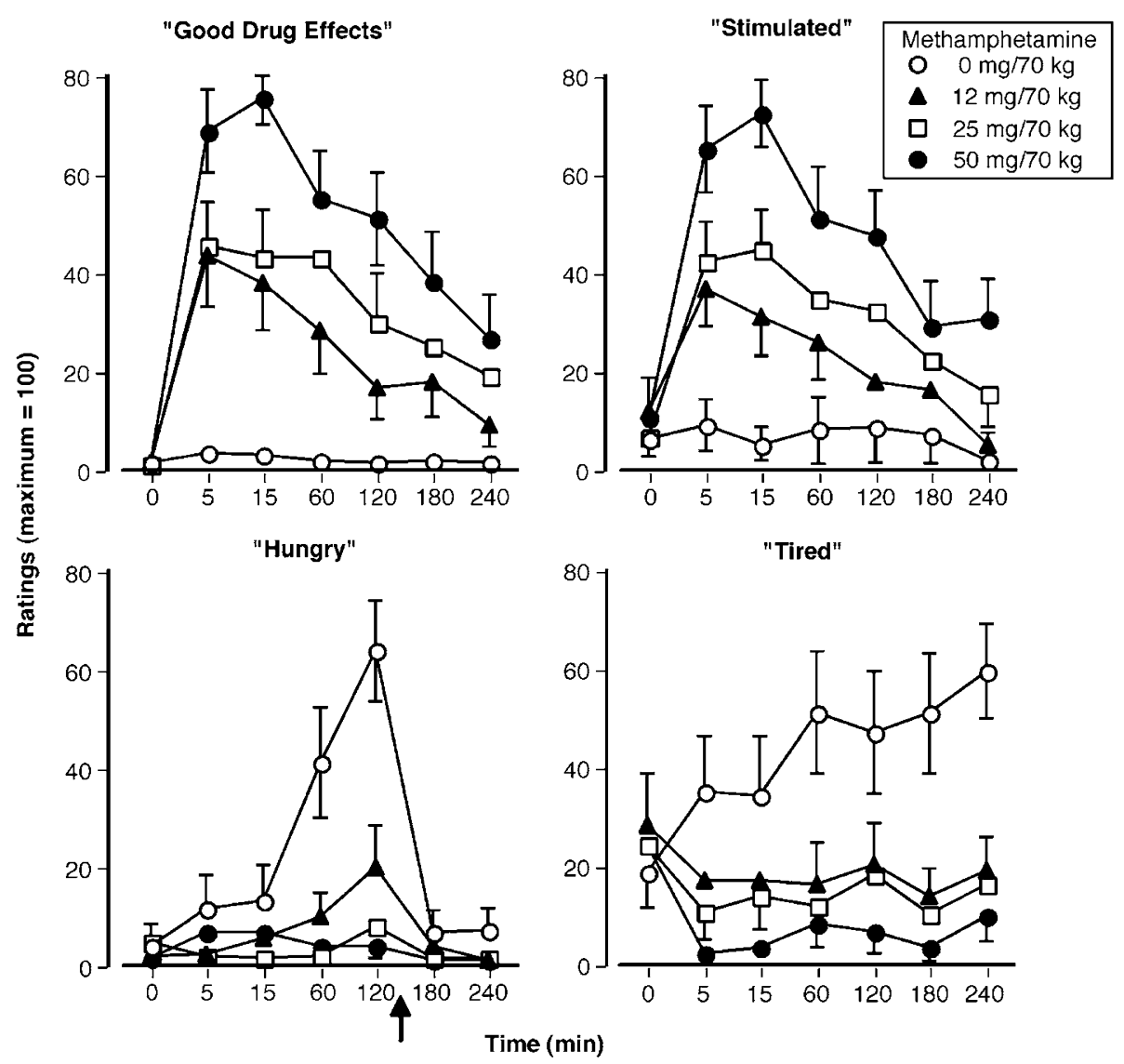

Figure 2 Selected subjective-effect ratings as a function of methamphetamine dose and time. Error bars represent one SEM. Overlapping error bars were omitted for clarity. An arrow indicates the time that participants ate lunch.

Relative to placebo, all active methamphetamine doses produced significant decreases on these ratings $(P<0.006)$. Similar to peak cardiovascular data, peak subjective-effect ratings were observed $15 \mathrm{~min}$ after methamphetamine administration. Table 1 summarizes other significant effects observed on the visual analog questionnaire.

Figure 3 demonstrates that methamphetamine produced dose-related effects on the DEQ rating assessing participants' desire to take the drug again $(\mathrm{F}(3,30)=14.01$, $P<0.001)$ and on the question probing how much participants were willing to pay for the dose received during the session $(F(3,30)=10.39, P<0.001)$. Similarly, methamphetamine significantly increased other DEQ ratings, and these effects are summarized in Table 1.

\section{Psychomotor/Cognitive Performance Effects}

Figure 4 shows how methamphetamine altered performance over time on selected measures. As can be seen, methamphetamine improved performance on both of the selected tasks. On the DAT, all active methamphetamine doses decreased the mean hit latency and increased the maximum tracking speed $(P<0.05)$. On the DSST, only the two intermediate doses (12 and $25 \mathrm{mg}$ ) significantly improved performance. Relative to placebo, both doses increased the total number of trial attempts and correct responses
$(P<0.03)$. No other significant performance effects were noted.

\section{DISCUSSION}

The major finding from the present investigation was that intranasal methamphetamine produced primarily positive effects on psychological measures (ie subjective-effect ratings and psychomotor/cognitive tasks), while systematically increasing methamphetamine plasma concentrations and cardiovascular measures. Peak cardiovascular and subjective effects occurred within 15 min after methamphetamine was insufflated, but peak methamphetamine plasma concentrations were not observed until $4 \mathrm{~h}$ postdrug administration. These findings are consistent with results reported by Harris et al (2003), who studied the effects of a single intranasal methamphetamine dose $(50 \mathrm{mg})$. Important concerns associated with the study by Harris et al, however, were the lack of a placebo condition and the simultaneous administration of intranasal methamphetamine with deuterated i.v. methamphetamine, which complicated data interpretation. The current data address these issues by demonstrating for the first time that intranasal methamphetamine produces dose-dependent effects on cardiovascular and subjective measures in regular users of the drug. Moreover, the present data show that metham- 
Table I Peak Methamphetamine Effects on the VAS and Drug-Effect Questionnaire

Methamphetamine conditions

\begin{tabular}{|c|c|c|c|c|c|c|c|}
\hline \multirow[b]{2}{*}{ Measure } & \multirow{2}{*}{$\begin{array}{c}\text { Pbo } \\
\text { Mean (SEM) }\end{array}$} & \multicolumn{2}{|c|}{$12 \mathrm{mg}$} & \multicolumn{2}{|c|}{$25 \mathrm{mg}$} & \multicolumn{2}{|c|}{$50 \mathrm{mg}$} \\
\hline & & Mean (SEM) & F-Value & Mean (SEM) & F-Value & Mean (SEM) & F-Value \\
\hline Alert & $58.36(8.36)$ & $76.00(7.54)$ & $8.87 *$ & $75.00(5.92)$ & $7.89 *$ & $87.55(4.07)$ & $24.27 *^{\dagger}$ \\
\hline Content & $57.64(7.09)$ & $56.18(3.61)$ & 0.07 & $59.64(4.72)$ & 0.13 & $72.27(5.42)$ & $6.83 * 8 \dagger$ \\
\hline Good drug effect & $4.36(1.45)$ & $46.46(10.92)$ & $21.04 *$ & $58.27(6.62)$ & $34.51 *$ & $78.64(5.4 I)$ & $65.51 * \$^{\dagger} \dagger$ \\
\hline Heart beating faster & II.27 (5.72) & $27.18(10.25)$ & 3.54 & $31.82(10.30)$ & $5.90 *$ & $43.18(11.87)$ & | $4.23 *$ \\
\hline High & $7.00(2.4 I)$ & $42.18(8.93)$ & 16.69* & $55.82(6.43)$ & $32.13 *$ & $73.18(7.21)$ & $59.04 * 8 \dagger$ \\
\hline Jittery & $7.36(3.66)$ & $22.73(9.42)$ & $4.38 *$ & | $4.73(7.85)$ & 1.01 & $24.82(8.56)$ & $5.65 *$ \\
\hline Nose burning & $2.60(1.26)$ & $10.50(7.02)$ & 0.90 & $23.70(8.24)$ & $6.42 *$ & $28.00(9.28)$ & $9.30 * 8$ \\
\hline \multicolumn{8}{|c|}{ Items on which methamphetamine decreased VAS ratings } \\
\hline Hunger & $70.27(8.24)$ & $27.73(7.94)$ & $23.15 *$ & $12.82(6.96)$ & $42.23 *$ & $10.82(4.46)$ & $45.22 *$ \\
\hline Irritable & $37.55(10.62)$ & $24.73(7.85)$ & 2.41 & $36.82(9.63)$ & 2.91 & । $8.27(7.75)$ & $5.45 *{ }^{\dagger}$ \\
\hline Sleepy & $74.64(10.47)$ & $33.64(10.64)$ & 13.79* & $33.82(11.03)$ & $13.67 *$ & $28.27(8.78)$ & 17.64* \\
\hline Tired & $72.09(\mid 1.11)$ & $44.73(9.99)$ & $8.63 *$ & $27.73(10.90)$ & $22.69 *$ & $32.55(8.36)$ & |8.03* \\
\hline Unmotivated & $45.73(12.13)$ & $22.46(9.59)$ & 3.91 & $25.46(11.12)$ & 2.97 & $13.36(5.74)$ & $7.56 *$ \\
\hline MA craving & $79.00(10.11)$ & $71.80(11.62)$ & 2.84 & $70.00(11.53)$ & 4.44* & $71.30(11.80)$ & 3.25 \\
\hline \multicolumn{8}{|l|}{ Drug-effect questionnaire } \\
\hline
\end{tabular}

Abbreviations: Pbo, Placebo; VAS, visual analog scale; MA, methamphetamine.

$* P<0.05$, significantly different from placebo.

$\$_{P}<0.05$, significantly different from $12 \mathrm{mg}$.

$\dagger^{\dagger}<0.05$, significantly different from $25 \mathrm{mg}$.

DEQ: Desire to Take Drug Again

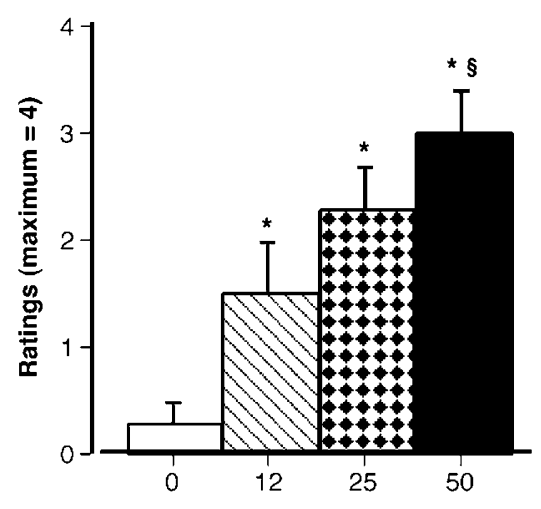

How much would you pay?

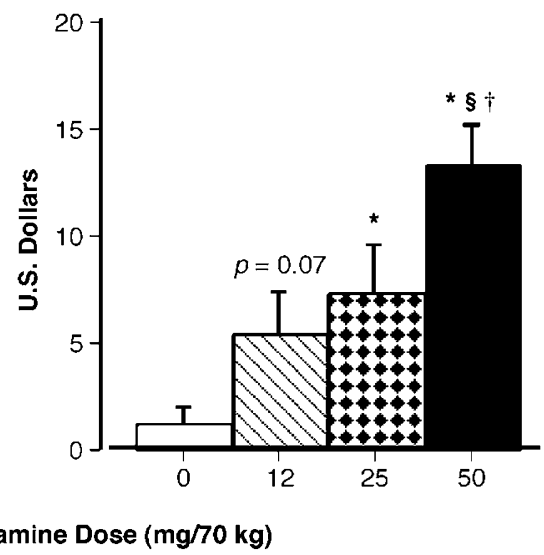

Figure 3 Selected subjective-effect ratings as a function of methamphetamine dose and time. Error bars represent one SEM. Overlapping error bars were omitted for clarity. An * indicates significantly different from placebo $(P<0.05)$. An ${ }^{\S}$ indicates significantly different from $12 \mathrm{mg} / 70 \mathrm{~kg}(P<0.05)$. An ${ }^{\dagger}$ indicates significantly different from $25 \mathrm{mg} / 70 \mathrm{~kg}(P<0.05)$. 
DAT: Hit Latency
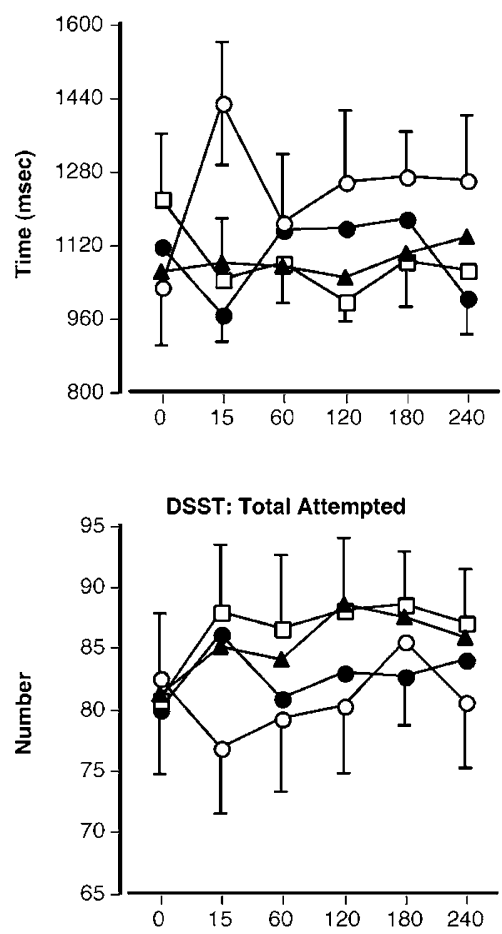

DAT: Maximum Speed

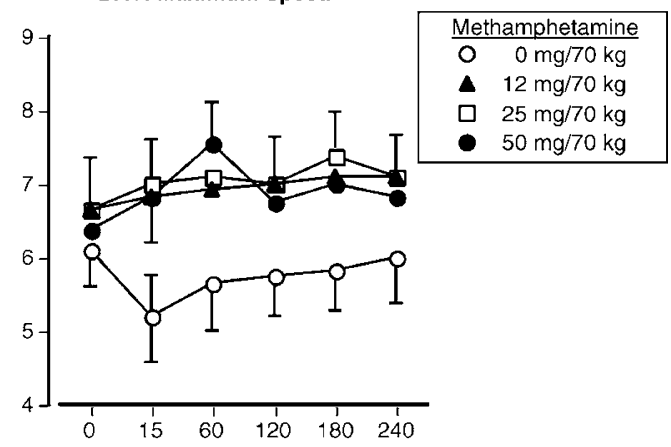

DSST: Total Correct

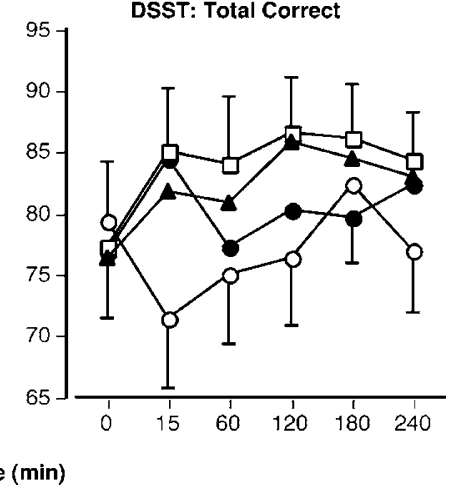

Figure 4 Selected performance effects as a function of methamphetamine dose and time. Error bars represent one SEM. Overlapping error bars were omitted for clarity.

phetamine enhanced performance on some psychomotor/ cognitive tasks. In general, methamphetamine-related effects on performance endured throughout the entire 4-h period that performance was assessed following methamphetamine administration, and the 12 - and $25-\mathrm{mg}$ doses improved performance to a greater extent than did the 50-mg dose. Importantly, methamphetamine, at all doses examined, did not produce any significant performance disruptions.

As expected, intranasal methamphetamine consistently enhanced feelings of euphoria and mood (eg as measured by ratings of 'good drug effect' and 'content') and decreased verbal reports of tiredness and sleepiness. These findings are in agreement with data from previous studies examining subjective effects produced by acute methamphetamine administered via the oral (Johnson et al, 1999; Comer et al, 2001; Hart et al, 2001a), i.v. (Mendelson et al, 1995; Johnson et al, 2005a; Newton et al, 2006), and smoked (Cook et al, 1993; Harris et al, 2003) routes of administration. Unlike the delayed time course of effects produced by oral methamphetamine, the onset of subjective effects produced by intranasal methamphetamine was rapid, occurring within minutes after administration. This feature most likely contributes to the recent increased frequency of abuse of intranasal methamphetamine because a rapid onset of drug actions is thought to be an important abuse liability determinant (Hatsukami and Fischman, 1996). Although the onset of peak effects produced by intranasal methamphetamine is somewhat slower than those of i.v. and smoked methamphetamine, it might be predicted that the abuse potential associated with methamphetamine administered via each of these routes is similar. Additional studies comparing the reinforcing effects (self-administration) of intranasal methamphetamine with reinforcing effects of i.v. and smoked methamphetamine are needed to better address this issue.

Consistent with subjective-effect data, psychomotor/ cognitive performance was improved on several measures following methamphetamine administration. Methamphetamine improved visuospatial processing (as measured by DSST) and vigilance and reaction time (as measured by the DAT). To our knowledge, this is the first published investigation of acute intranasal methamphetamine-related effects on performance, making it difficult to relate the present findings with previous research. Nevertheless, the data generally agree with results from studies assessing the effects of oral (Johnson et al, 2000; Hart et al, 2002; Silber et al, 2006) and i.v. (Johnson et al, 2005b) methamphetamine on performance. These data are also consistent with findings from studies that have assessed the effects of oral methamphetamine on performance of sleep-deprived individuals and research participants subjected to abrupt work-shift schedule changes (Wiegmann et al, 1996; Hart et al, 2003, 2005). One potential drawback, however, associated with the performance-enhancing effects of intranasal methamphetamine is that this characteristic of the drug might actually contribute to or enhance its abuse liability. Findings from numerous studies demonstrate that the reinforcing effects of stimulants are increased when performance is perceived to be improved following drug 
administration (Silverman et al, 1994a, b; Comer et al, 1996; Jones et al, 2001; Stoops et al, 2005a, b).

The finding that methamphetamine-related subjective and physiological effects peaked markedly earlier than methamphetamine plasma levels is intriguing. This raises potential concern because anecdotal reports indicate that methamphetamine is commonly abused in multiple dose cycles, with an inter-dose interval of $0.5-3 \mathrm{~h}$, which may continue for several days (Angrist, 1994; Gawin and Khalsa-Denison, 1996; Cho et al, 2001). Thus, in the natural ecology, some methamphetamine users may be exposed to methamphetamine plasma levels considerably larger than those reported here, and this might increase the likelihood of toxicity. It is possible that data collected following repeated administration of intranasal cocaine can inform this issue because cocaine is also taken in a binge pattern and often with a shorter interval between dosings than methamphetamine. Foltin and colleagues have demonstrated that significant acute tolerance develops in response to repeated cocaine dosing (Foltin et al, 1988; Foltin and Haney, 2004), which might suggest a similar situation following multiple intranasal methamphetamine dose administrations. It is important to note that although both cocaine and methamphetamine when used intranasally produce rapid changes in cardiovascular effects, the duration of cardiovascular effects of a single dose of cocaine is much shorter $(30-50 \mathrm{~min})$ than the duration of the cardiovascular effects of a single dose of methamphetamine $(>240 \mathrm{~min})$. The duration of action is a critical determinant of potential toxicity associated with both drugs and suggests that the toxic effects of cocaine and methamphetamine may manifest differently. Future studies should compare the effects produced by intranasal cocaine and methamphetamine and evaluate the effects of repeated intranasal methamphetamine administration. One important question that should be assessed is whether cardiovascular measures are substantially increased following multiple methamphetamine doses.

In conclusion, the current findings indicate that intranasal methamphetamine produced orderly effects on psychological and physiological measures with a rapid onset of effects. The fact that the drug produced primarily positive effects on psychological measures without producing noticeable adverse consequences may help to explain anecdotal reports of intranasal methamphetamine abuse. The data also show that methamphetamine plasma concentrations were dose dependently increased several hours after drug administration, when measures of euphoria were returning to baseline levels. The dissociation between methamphetamine plasma concentrations with cardiovascular measures and positive subjective effects might have important implications for potential toxicity after repeated doses.

\section{ACKNOWLEDGEMENTS}

The medical assistance of Dr Benjamin R Nordstrom and technical assistance of Gydmer Perez are gratefully acknowledged. This research was supported by a grant from the National Institute on Drug Abuse (DA19559).

\section{DISCLOSURE/CONFLICTS OF INTEREST}

The authors declare that except for the income received from our primary employer no financial support or compensation has been received from any individual or corporate entity over the past 3 years for research or professional service and there are no personal financial holdings that could be perceived as constituting a potential conflict of interest.

\section{REFERENCES}

Angrist B (1994). Amphetamine psychosis: clinical variations of the syndrome. In: Cho AK, Segal DS (eds). Amphetamine and its Analogues. Academic Press: San Diego. pp 387-414.

Cho AK, Melega WP, Kuczenski R, Segal DS (2001). Relevance of pharmacokinetic parameters in animal models of methamphetamine abuse. Synapse 39: 161-166.

Comer SD, Collins ED, Fischman MW (1997). Choice between money and intranasal heroin in morphine-maintained humans. Behav Pharmacol 6: 677-690.

Comer SD, Haney M, Foltin RW, Fischman MW (1996). Amphetamine self-administration by humans: modulation by contingencies associated with task performance. Psychopharmacology 127: 39-46.

Comer SD, Hart CL, Ward AS, Haney M, Foltin RW, Fischman MW (2001). Effects of repeated oral methamphetamine administration in humans. Psychopharmacology 155: 397-404.

Community Epidemiology Work Group (CEWG) (2005). Epidemiologic Trends in Drug Abuse Volume I: Proceedings of the Community Epidemiology Work Group, NIH Pub. No. 05-5364A US Government Printing Office: Washington, DC.

Community Epidemiology Work Group (CEWG) (2007). Epidemiologic Trends in Drug Abuse Volume I: Proceedings of the Community Epidemiology Work Group, NIH Pub. No. 07-5879A US Government Printing Office: Washington, DC.

Cook CE, Jeffcoat AR, Hill JM, Pugh DE, Patetta PK, Sadler BM et al (1993). Pharmacokinetics of methamphetamine selfadministered to human subjects by smoking S-(+)-methamphetamine hydrochloride. Drug Metab Dispos 21: 717-723.

Domier CP, Simon SL, Rawson RA, Huber A, Ling W (2000). A comparison of injecting and noninjecting methamphetamine users. J Psych Drug 32: 229-232.

Foltin RW, Fischman MW, Pedroso JJ, Pearlson GD (1988). Repeated intranasal cocaine administration: lack of tolerance to pressor effects. Drug Alcohol Depend 22: 169-177.

Foltin RW, Haney M (2004). Intranasal cocaine in humans: acute tolerance, cardiovascular and subjective effects. Pharmacol Biochem Behav 78: 93-101.

Gawin FH, Khalsa-Denison ME (1996). Is craving mood-driven or self-propelled? Sensitization and 'street' stimulant addiction? NIDA Res Monogr 163: 224-250.

Halkitis PN, Parsons JT, Wilton L (2003). An exploratory study of contextual and situational factors related to methamphetamine use among gay and bisexual men in New York City. J Drug Issues 33: 413-432.

Harris DS, Boxenbaum H, Everhart ET, Sequeira G, Mendelson JE, Jones RT (2003). The bioavailability of intranasal and smoked methamphetamine. Clin Pharmacol Ther 74: 475-486.

Hart CL, Haney M, Foltin RW, Fischman MW (2002). Effects of the NMDA antagonist memantine on human methamphetamine discrimination. Psychopharmacology 164: 376-384.

Hart CL, Haney M, Nasser J, Foltin RW (2005). Combined effects of methamphetamine and zolpidem on behavior of shift workers. Pharmacol Biochem Behav 81: 559-568. 
Hart CL, Haney M, Vosburg SK, Comer SD, Gunderson EW, Foltin RW (2006). Modafinil attenuates disruptions in cognitive performance during simulated night shift work. Neuropsychopharmacology 31: 1526-1536.

Hart CL, van Gorp WG, Haney M, Foltin RW, Fischman MW (2001b). Effects of acute smoked marijuana on complex cognitive performance. Neuropsychopharmacology 25: 757-765.

Hart CL, Ward AS, Haney M, Foltin RW, Fischman MW (2001a). Methamphetamine self-administration by humans. Psychopharmacology 157: 75-81.

Hart CL, Ward AS, Haney M, Nasser J, Foltin RW (2003). Methamphetamine attenuates disruptions in performance and mood during simulated night shift work. Psychopharmacology 169: $42-51$.

Hatsukami DK, Fischman MW (1996). Crack cocaine and cocaine hydrochloride. Are the differences myth or reality? JAMA 276: 1580-1588.

Johnson BA, Ait-Daoud N, Wells LT (2000). Effects of isradipine, a dihydropyridine-class calcium channel antagonist, on D-methamphetamine-induced cognitive and physiological changes in humans. Neuropsychopharmacology 22: 504-512.

Johnson BA, Roache JD, Ait-Daoud N, Wallace C, Wells L, Dawes $M$ et al (2005a). Effects of isradipine, a dihydropyridine-class calcium-channel antagonist, on d-methamphetamine's subjective and reinforcing effects. Int J Neuropsychopharmacol 8: 203-213.

Johnson BA, Roache JD, Ait-Daoud N, Wallace C, Wells LT, Wang $\mathrm{Y}$ (2005b). Effects of isradipine on methamphetamine-induced changes in attentional and perceptual-motor skills of cognition. Psychopharmacology 178: 296-302.

Johnson BA, Roache JD, Bordnick PS, Ait-Daoud N (1999). Isradipine, a dihydropyridine-class calcium channel antagonist, attenuates some of d-methamphetamine's positive subjective effects: a preliminary study. Psychopharmacology 144: 295-300.

Jones HE, Garrett BE, Griffiths RR (2001). Reinforcing effects of oral cocaine: contextual determinants. Psychopharmacology 154: 143-152.

Kelly TH, Foltin RW, Emurian CS, Fischman MW (1993). Performance-based testing for drugs of abuse: dose and time profiles of marijuana, amphetamine, alcohol, and diazepam. J Anal Toxicol 17: 264-272.
McLeod DR, Griffiths RR, Bigelow GE, Yingling J (1982). An automated version of the digit symbol substitution test (DSST). Behav Res Methods Instrum 14: 463-466.

Mendelson J, Jones RT, Upton R, Jacob P (1995). Methamphetamine and ethanol interactions in humans. Clin Pharmacol Ther 57: 559-568.

Miller TP, Taylor JL, Tinklenberg JR (1988). A comparison of assessment techniques measuring the effects of methylphenidate, secobarbital, diazepam, and diphenhydramine in abstinent alcoholics. Neuropsychobiology 19: 90-96.

Newton TF, De La Garza II R, Fong T, Chiang N, Holmes TH, Bloch DA et al (2005). A comprehensive assessment of the safety of intravenous methamphetamine administration during treatment with selegiline. Pharmacol Biochem Behav 82: 704-711.

Newton TF, Roache JD, De La Garza II R, Fong T, Wallace CL, Li $\mathrm{SH}$ et al (2006). Bupropion reduces methamphetamine-induced subjective effects and cue-induced craving. Neuropsychopharmacology 31: 1537-1544.

Silber BY, Croft RJ, Papafotiou K, Stough C (2006). The acute effects of d-amphetamine and methamphetamine on attention and psychomotor performance. Psychopharmacology 187: 154-169.

Silverman K, Kirby KC, Griffiths RR (1994a). Modulation of drug reinforcement by behavioral requirements following drug ingestion. Psychopharmacology 114: 243-247.

Silverman K, Mumford GK, Griffiths RR (1994b). Enhancing caffeine reinforcement by behavioral requirements following drug ingestion. Psychopharmacology 114: 424-432.

Stoops WW, Lile JA, Fillmore MT, Glaser PEA, Rush CR (2005a). Reinforcing effects of methylphenidate: influence of dose and behavioral demands following drug administration. Psychopharmacology 177: 349-355.

Stoops WW, Lile JA, Fillmore MT, Glaser PEA, Rush CR (2005b). Reinforcing effects of modafinil: influence of dose and behavioral demands following drug administration. Psychopharmacology 182: 186-193.

Wesnes K, Warburton DM (1983). Effects of smoking on rapid information processing performance. Neuropsychobiology 9: 223-229.

Wiegmann DA, Stanny RR, McKay DL, Neri DF, McCardie AH (1996). Methamphetamine effects on cognitive processing during extended wakefulness. Int J Aviat Psychol 6: 379-397. 